\title{
INFLUENCE OF EATING HABITS ON PEOPLE'S LIFE QUALITY
}

\author{
Arturs Medveckis ${ }^{1}$, Tamara Pigozne ${ }^{2}$ \\ ${ }^{1}$ Sociological Research Center, Liepaja University, Liela Street14, Liepaja, Latvia, e-mail: arturs.medveckis@liepu.lv \\ ${ }^{2}$ Scientific Institute of Pedagogy, University of Latvia, Jurmalas Gatve76, Riga, Latvia
}

\begin{abstract}
Life quality requirement and indicators is person`s health, which is affected by food quality and eating habits. Healthy food consumption is related not only with food quality standards, but it is influenced by social, economic and cultural factors, in specific cases by physiological, inherited or gained eating habit features corresponding to persons age. Complying with these features, for example, new-born nourishment, different product or substance intolerance, or illnesses etc. determine the intake of necessary nourishment. Eating habits are analysed together with other healthy life style components, as well as physical, social and educational environment influence factors on physical and psychological well-being. In a life quality context researchers have studied eating habits and factors that influence them already for a while, creating a study basis to ascertain the dynamics of behaviour change, as well as carrying out quantitative and qualitative data comparative analysis. Empiric data basis include different age groups, starting from study on factors affecting new-born life quality from 2007, which continued at preschool and elementary school age group from 2008 and at secondary school level from 2011. The aim of this article is to present the outcome of longitudinal study on the eating habits and their impact on quality of life. Conclusions and recommendations for unhealthy habit change can be found in complex approach, focusing on education improvement aspect interrelations with institutional solutions, providing healthy food accessibility and limiting the unfavourable factors.
\end{abstract}

Keywords: life quality, healthy lifestyle, food quality, eating habits, education.

\section{Introduction}

The quality of life in the context of stratification and agedness of today`s society is emphasized both in European and in Latvian strategic planning documents. According to ,economic spurt” as set leading motive and growth of national economy, theories supporting human securitability and growth as implementation of set priorities, limited labour force, financial and natural resources turning into competitive products and services, in order to achieve the main goal - growth of life quality (National development Plan of Latvia for 2014-2020, 2012), it is essential to carry out comparative studies regularly to identify the dynamics of populations life quality.

Notion „life quality" has no single definition. Therefore there is no single understanding of how to characterize the life quality. Although until the middle of 20th century economic indicators were uppermost in the development, more and more often opinion was expressed that economic growth is not a goal in itself, if it doesn't promote well-being and satisfaction with life, because not always the growth of material prosperity creates society of happy people (Kîlis, 2007). During the second half of 20th century strengthened the opinion that well-being is not defined only by income, but it also includes such areas as security, climate, health, education (Hasan, 2007). Huge impact on life quality has surrounding environment (Biagi et al., 2006). During the second half of 20th century such social conditions that impact life quality subjective elements as participation, entertainment, capacity to act (Lanteigne, 2005) and opportunity (Seed, Lloyd, 1997) were highlighted. Opportunity in this context is not coincidence or luck, but rather a choice, access to resources, services and goods that provide sufficient standard of living. As a result quality of life forms from many components, which objectively affect people's lives and subjectively manifests as level of life satisfaction, and, incorporating in itself the economic indicators, centre around opportunities and capacity to act of individual (Biagi et al., 2006; Meiselman, 2016). Life quality is complex social, economic, political notion that contain wide range of living conditions of state residents. It is characterized by the level of consumption and by range and quality of social services available to person, as well as by the possibility to obtain the education, to live long and healthy life, to participate in state's political life, and by the eradication of discrimination based on sex, ethnic, religion, disability, sexual orientation and age. Therefore person is able to embrace its potential for the creation of well-being for the whole society. Life quality is defined by state's nature, economic, social and political environment, which can be characterized with different indicators (National Development Plan of Latvia for 2014-2020). Static and dynamic understanding characteristic to life quality (Tisenkopfs, 2006):

- Static understanding: life quality is achievable or achieved goal or result. In this aspect life quality will always be insufficient and there is big possibility that it will obtain patterns of consumerisms.

- Dynamic understanding: life quality is process of improvement of life itself - set of intentions and activities that are directed towards raising the wellbeing, using the opportunities, perfection of abilities. It depends on capacity to act and it provides satisfaction.

Ferrell (1995) has defined life quality as feeling of comfort that is established by four areas: life quality consists of physical, mental, social and spiritual feeling of comfort. Food is one of the factors that influence subjective well-being (Grunert et al., 2007; Schnettler et al., 2015), differentiating food- and pleasure-related well-being and food- and healthrelated well-being (Guillemin et al., 2016).

Siekierski and Ponchio (2014) emphasize that according to studies where demand for uptake of nutrients is simulated (Behrman, Deolalikar, 1990; Barrett, 2002) 
and according the studies about link between food choices and health and labour market (Pitt et al., 1990), as well as body weight (Cawley, 2004; Cutler et al, 2003), food in economy is both commodity and investment, because with taste, texture and feeling of satiety food gives instant satisfaction, but it is also related with health and wellbeing, costs and benefits.

Since food is essential part of quality of life and unhealthy nourishment can leave a negative effect on health (Jackson et al., 2005), along with growing public concerns about eating habits more and more discussions occur on necessity to increase the proportion of health education in educational programs in Latvia, as well as on requirements for food quality in educational institutions (Government regulations No.172), hospitals, providing balanced diet, limiting food colorants, preservatives, sweeteners, flavour enhancers, including amount of mononatrium glutamate (E621), preservatives, sugar and salt. Ministry of Health of Republic of Latvia has made differentiated recommendations for different age groups - infants, children aged 2 to 18 years, adults, persons who are older than 60 years, as well as it has indicated the recommended energy and nutrient intakes for citizens of Latvia.

Food choices and eating habits are influenced by different factors, but most significant are life style and culture (Siekierski, Ponchio, 2014; Ares et al., 2016).

In the context of this study understanding of life style is associated with how person lives (Sheth et al., 1999), spends his time and money (Kotlers, Keller, 2006; Blackwell et al., 2001), reflects on what person thinks of life, values, how he acts and behaves (Dias, 2003), creates self-image, which is defined by previous experience, strains and current situation, social status, subculture, motives, emotions and that is influenced by economic, demographic, social, nutritional, educational, historical and climatic factors, putting forward such indicators as action (work, hobby, social events, vacation, entertainment, shopping, sports), interests (family, home, work, relaxation, food, media, achievements), opportunities (social questions, politics, economics, education, products, culture) and demographic (age, education, income, occupation, size of family, home, geography) (Hawkins et al., 2007; Wells, Tigert, 1971).

Social stratification is based on class division: upper class, upper middle class, where success strategy is the dominant one, and lower middle class, lower class, where survival strategy is dominant (Meņšikovs, 2006). Whereas culture, that has both roots in religion and secular trend, influences fashion and life style choices, and at some point in life it can influence persons behaviour, becoming a habit and at certain conditions to create a tradition. Fashion displays person's reaction on modern life pressure (Rožkalne, 2006).

The aim of this research is to determine changes in people`s eating habits and their influence on life quality in the period from 2007 to 2017.

\section{Materials and Methods}

Liepaja University Sociological research centre`s longitudinal study was started on 2007 in Liepaja and in Kurzeme region (Latvia). 1804 respondents from particular city and its surrounding territory were involved. They were both students and experts, who represent all age groups, defining the frame for study that is related to children and youth life quality perspective - healthy life style, nourishment quality and eating habits. Study consists of four stages:

I stage New-born life quality perspective - study in Kurzeme and Liepaja carried out in 2007. Surveyed unit distribution per month was calculated according to proportion of birth each month. Respectively each year data from medical records were collected, it was transferred to anonymous forms according to personal data protection requirements. As a result N 1141 units were selected randomly, they sorted by the years according to expectations, and were supplemented by five independent medical personnel expert interviews;

II stage Study on population reproduction qualitative aspect in Kurzeme and Liepaja carried out in 2008. In order to study preschool and elementary school children life quality aspects qualitative research method was used -6 focus group interviews and expert interviews, 34 focus group interview participants and 6 experts participated. At preschool level there were two independent focus groups consisting of preschool teachers, psychologists, medics, social workers, parents. Schools were chosen randomly -3 in Liepaja and one in Kurzeme region - focus group participant content was similar, sometimes school administration representatives participated.

III stage Youngsters' future plans and their implementation possibilities in Kurzeme and Liepaja. Population reproduction study in Kurzeme and Liepaja carried out in 2011. Survey was carried out between elementary school graduates $\left(9^{\text {th }}\right.$ class) and secondary school graduates $\left(12^{\text {th }}\right.$ grade $)$ in the same schools where previous 2008 study was carried out using the survey method - students filled the questionnaires in their classes (N 338).

IV stage Youngster's life quality and healthy lifestyle aspects in Kurzeme and Liepaja carried out in 2017. To find the answers on set questions student questionnaire was carried out according to methodology used during $3^{\text {rd }}$ stage of study (N 266). Experts and 2 focus group consisted from 14 respondents: general education school pedagogues, school principals, deputy directors on study and education work, medical workers (family doctors, dietician, nurses, and parents - members of parent councils, university pedagogy doctors - experts).

During the collection of data mixed methods approach was implemented, therefore securing the triangulation.

In the basis of developed coding system that consisted of profile codes and content (conceptual) codes, there are categories / criteria and subcategories / indicators identified as a result of theoretical literature analysis: life quality philosophic understanding (static and dynamic); lifestyle (relationship / interaction / 
communication, behaviour / action, interests, stress); culture (tradition / rituals, table culture, values and life quality strategies (survival (ensuring the basic needs, adaptation to conditions success (capacity to act, possibilities of self-realization)). Respondent profile is formed by status (new-born (1141), pupils (656), pedagogue (24), parent (9), expert (6); gender (female (869), male (935), residence (Liepaja (1153), Kurzeme region (651)) and social layer (upper (55), upper middle (684) lower middle (976), lower (89)).

For the self-assessment of respondent life quality, wellbeing, health and stress Likert scale was used.

Data processing methods:

- Processing of qualitative data in the AQUAD (Huber, Gürtler, 2003) software environment: frequencies, linkages, and implicants.

- Processing of quantitative data in the SPSS 21.0 (Statistical Package for Social Sciences) software environment: Kolmogorov-Smirnov test for definition of result groups, cross tabulation and Chi-Square test to define relationships, KruskalWalis H-test to define differences among respondent groups, Kendall's tau-b correlation analysis to define correlations among categories.

\section{Results and Discussion}

In a study „Newborn quality of life perspective" (Markausa et al., 2007) done by Liepaja Pedagogy academy Social science department Sociological research centre researchers focused on factors influencing and characterizing the new-born life quality perspective. They admitted that ,Fundaments of child's life expectancy and quality are laid during the pregnancy, they are influenced by mothers overall health condition, nutrition, emotional well-being etc." (Markausa et al., 2007, 4). Neonatal pathology, disease causing factor analysis results correlated with mother`s life style, including nourishment quality, bad habits (smoking, alcohol abuse, reproductive behaviour) etc. $(p=0.000 ; r=0.79)$, while drawing attention also to a way infant is nurtured starting from the first minutes of his life. The study found that infant feeding not always is mothers choice, it can be influenced both by child's and by mother's health condition.

In 2017 study in interview with neonatologist with 35 years long experience it was confirmed and found that there is link between life quality dynamic understanding and values:

"Clinical studies have demonstrated the importance of breast-feeding from the first hours of child's life, which is difficult to compensate with other nutrition. Lately it can be noticed that desire to breast-feed is growing, which to some extent can be called a good fashion tendency. It can be explained by increasing number of publication on social media about new mother's life style. It lacks deeper knowledge, but it's alright..."

However family doctor, paediatrician with 30 years' work experience has noticed not only the positive tendency in new-born feeding, but also pointed at problems that new mother`s face. It allowed to establish a correlation in qualitative data processing AQUAD software environment between categories life quality philosophy, culture and strategy or, more precisely, subcategories - life quality dynamic understanding, health as value and survival strategy: "There is no indication that demand for infant specialized food from the parents would have grown. Mothers are trying to breast-feed. Other issue is that while child grows he might need an additional feeding. I assume that restrictions on infant nourishment commercials have partially promoted the positive change. There are also families where mother's life style and economic situation do not contribute to healthy nourishment choices. Poor people can be not only poorly educated, they can also live in partial families."

Infant feeding choice is influenced by recommendations from medical experts, "pressure from society" as fashion tendency or etiquette, but not always by thorough knowledge about the influence that healthy nourishment has on new-born life quality, well-being and health.

At all life stages of parents health education is necessary. It would reduce the negative influence of commercialization related to necessary health promoting life style, including food choices and regime. "Study on population reproduction qualitative aspect in Kurzeme and Liepaja" (Markausa et al., 2008) is logical continuation of the first stage. During the study it was found that qualitative balanced nourishment provided in educational institutions at the preschool and elementary school level for children contrasts with eating habits in families.

Results of the surveys from 2008 and 2017 show that healthy nourishment and life style is easier to provide in families with high or average living standard, but there are potential risks also for families with high and average income level per family member. Selfidentification with or objective belonging to upper or middle social layer is not the decisive factor for healthy diet. Besides catering at educational institutions, especially at children parties, unhealthy food dominates as a main snack: pizza, pastries, crisps, sweetened soda drinks, although kids at kindergarten level already know what is healthy and what's not a healthy food. It was confirmed by a preschool pedagogue with 35 years' experience during the focus group interview:

"If there are sandwiches with salami, salad and carrots on the table then sandwiches will disappear first. In the group only one child eats salad and carrots. Sweet drinks are on demand. It is the mirror of family. If parents offer to go to Hesburger for a lunch, then it is obvious, that they are doing so because it is easier. Today it is no rarity that kids who are going home have pack of crisps or some colourful candy in their hands." Very often parents take their children to sports trainings after work, or to different artistic creativity hobby groups. On the way from educational institution to the place of extracurricular activity very often children eat fast food, sweets, drink sweetened drinks. Also after the 
activity, which sometimes ends late in the evening, children have heavy meals before sleep:

"Usually those are late dinners. It depends on son's football trainings. After the kindergarten 3 times a week we walk to the sports hall and then back. It is a big load, but there are no complaints. Therefore last meal usually

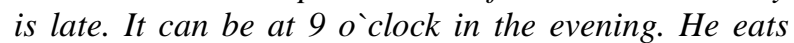
different soups, second course with meat, fish. Without objections he eats salad, tomatoes, and cucumbers. He does not like sweets very much." (Father of preschooler, 34 years old)

Younger students at the beginning of elementary school gladly eat meals provided at school, however later, when they have a pocket money it is obvious that children prefer to eat outside the school. During the teen years girls particularly are concerned about the looks. They show the tendency to lose weight by skipping the meals: "At the early classes there were free meals, everything happened centralized, but after the second grade I was paying. Also now school offers to eat during particular break and centralized, but my children do not choose that. Daughter keeps an eye on her weight. Because these are teen years, they pay attention to weights also because of peer pressure. There were times when she skipped meals to obtain the desired look, but it had opposite effect, until she realized that you have to eat regularly and cooked meals." (Mother of 2 children, 38 years old)

Preschool educational institutions and schools provide healthy and balanced diet, but parent life style, ambitions and fragmented knowledge about healthy nourishment do not promote good health for their children. Children are well informed about diet and unhealthy habits, but indiscriminate following of fashion tendencies and imitation of friend`s behaviour causes risks.

In 2011 study “Youngsters' future plans and their implementation possibilities in Kurzeme and Liepaja. Population reproduction study in Kurzeme and Liepaja" revealed significant connections between implementation of future plans and healthy eating habits:

○ Teachers believe that there are several related health, behaviour and school results problem causes: parent busyness and therefore minimal contact with their children; one of parents lack or absence; not sufficient, excessive, misbalanced diet; relationship with peers; family conditions (level of wealth, living conditions, relationship between children and parents); sedentary life.

- 9-12 ${ }^{\text {th }}$ grade questionnaires, where those who are facing career choices whether to continue studies or to start working were questioned, revealed the possible life style related risks, including health problems caused by diet and bad habits, which threatens the future profession choices.

Student life style is related with physical space and social environment around. Usually the physical space home, school and leisure - are united, but often students, who live in rural areas, use educational and leisure possibilities in nearest town. Distribution of time between time spent with parents at home, at school and at leisure activities is not constant. If student don `t miss school, then distribution of time for school in one age group is similar. Two variables are time spent at home and at leisure activities. When time spent on leisure activities grow, student needs money. Pocket money is usually spent on entertainment, sweets, cigarettes, while giving up on meals at school canteen.

2011 study revealed that approximately one third of students spend their money on sweets, two times more in ninth grade than in twelve grade (42.4\% and $21.4 \%)$. During secondary school spending pocket money on cigarettes and alcohol becomes more frequent. However 2017 study Youngster's life quality and healthy lifestyle aspects in Kurzeme and Liepaja shows that there are more smokers in eighth grade (78\%), smoking frequency varies $-20 \%$ admits that they are regular smokers (10-20) cigarettes per day. In comparison with 2008 , where $52.6 \%$ boys and $51.4 \%$ girls had encountered alcohol abuse, but at twelve grade $-76.7 \%$ boys and $73.7 \%$ girls, 2017 study revealed that at least $89 \%$ ninth graders and $73 \%$ secondary school students had consumed alcohol "because others in the group were drinking", which can be explained by the fact that usually motivated, success-oriented students continue studies in secondary school, while part of the ninth graders continue their education at vocational schools or find job.

Mother of two youngsters reveal that her children are supporters of active and healthy life style. She admits that youngsters are familiar with alcohol abuse, smoking and even drug abuse:

"Son quit secondary school because he wanted to study logistics at vocational school. The rumours say that $90 \%$ of boys are smoking. There are no indications that he has started, too. He acts disapprovingly. My daughter, when she was at sixth grade, told me that once during a field trip one girl fainted because she was smoking in the morning and had no breakfast before that. My children choose sports, not parties. Their friends have similar life style - they choose trainings, but, I guess, its half to half: others like parties, but not all of them. Secondary school students sometimes have alcohol at the parties, and not just that, other substances are being used, too. I don't want to believe that its only family's fault, its more influence from friends. Unfortunately also between those who do sports... Desire to try..."

Stress, sleepiness appears in 2017 study: 26\% ninth graders together with their peers or anonymously long hours during the night play interactive computer games: "Less in secondary school, but at $8^{\text {th }}$ and $9^{\text {th }}$ grade they "live" in their smart phones - in social networks. And those, who have trendy clothes and latest smart phone, they don't have the best grades. Their parents don't attend school meetings or attend very rarely. They don't have time or they don't live with their children. Maybe they just "pay-off" their children to earn the big money undisturbed." (Teacher, 28 years old) 
2017 study reveals that persons in youngster's close circle have similar life style, and that at secondary school $48 \%$ boys do sports.

Cultural aspect related to previous eating habits and traditional culture change under the pressure of open market economy and globalization. It is positive that fresh fruits, vegetables are available at any time of year, but as symbols of rush and globalization more and more rapidly fast food, exotic synthetic tastes enter one`s life style, which change the eating habits of a person. Popular culture, too, imposes its model, advertising weight loss diets, which sometimes include dietary supplements. They take focus away from the obesity reasons and problems caused by obesity. If somebody relates food intake only with calorie intake, then table culture - being together, discussing experiences, being in cosy atmosphere with aesthetic table setting - loses its significance. Unfortunately also school cafeterias and canteens usually use disposable dishes.

"More sustainable are family traditions related with holidays, however because of daily habits holiday dinners and rituals become more and more casual: people by convenience foods, ready-made dishes like pastries and cakes, therefore they prevent holiday rituals, but, instead, they focus on result - full table, and the result is achieved without big effort." (Expert, cultural anthropologist, 48 years old)

In 2017 study $12^{\text {th }}$ graders value health higher, comparing to $9^{\text {th }}$ graders $(\mathrm{p}=0.047)$.

Significance of health, which depends on their own choices and is related with dynamic paradigm, compared with 2011 study has increased among $12^{\text {th }}$ graders. For example, consumption of fruits and vegetables has raised from $46.5 \%$ in 2008 to $49.6 \%$ in 2017. However number of smokers increases in younger classes, but at $12^{\text {th }}$ grade it stays the same. In $9^{\text {th }}$ grade there were $49.1 \%$ non-smokers in 2008 , and only $42.9 \%$ in 2017.

Similar tendencies show non-use of alcohol, but way of socialization that was related to alcohol abuse is being compensated with excessive playing of computer games and spending time on social networks.

Health can be affected by eating regime. In 2011 study it was found that students try to eat during the school time $-43.5 \%$ students have lunch at school on regular basis, $18.6 \%$ go home, others use different possibilities: go out in town, sometimes home, buy something in the shop or make choices according to possibilities. Nearly one third $(32.0 \%)$ eat only at home - they don't eat almost all day long. Students avoid bringing food from home. 2017 study show tendency to takeaways from shops during the breaks, cafes, markets or at canteens, although school provides catering. It is related with wider range of meals offered at those places, students like to enjoy cafeteria atmosphere or they find food outside school tastier.

Kendall correlation analysis show that there is a correlation between life quality and criteria "life quality philosophical understanding" $(\mathrm{p}=0.000 ; \mathrm{r}=0.53)$, "lifestyle" $(p=0.000 ; \quad r=0.85)$, "culture" $(p=0.000$; $\mathrm{r}=0.62)$, and "success strategy" $(\mathrm{p}=0.000 ; \mathrm{r}=0.81)$, as well as between indicators "life quality dynamic understanding" $(\mathrm{p}=0.000 ; \mathrm{r}=0.57)$, "eating habits" $(\mathrm{p}=0.000 ; \mathrm{r}=0.66)$, "healthy balanced diet" $(\mathrm{p}=0.000$; $\mathrm{r}=0.73)$, "health as value" $(\mathrm{p}=0.000 ; \mathrm{r}=0.55)$, "capacity to act" ( $p=0.000 ; r=0.71)$, and "possibilities of selfrealization" ( $p=0.000 ; r=0.69)$. Quantitative secondary data is confirmed by qualitative data - processing of qualitative data in the AQUAD software environment regularity condition was identified - life quality is affected by its dynamic understanding, eating regime, interests, healthy balanced diet, health as value, capacity to act and possibilities for self-realization.

Determination of Chi-Square test result relationship indicates that statistically very significant link exists between respondent's profile - social class and indicators "healthy balanced diet" $\left(\chi^{2}(2)=38.177\right.$; $\mathrm{p}=0.002)$, "life quality dynamic understanding" $\left(\chi^{2}(2)=29.139 ; \quad \mathrm{p}=0.009\right), \quad$ "success strategy" $\left(\chi^{2}(2)=34.121 ; p=0.005\right)$. Kruskal-Walis H-test for identification of result differences between respondent groups indicate that statistically maximally important differences $(p=0.000)$ between social classes and eating habits exist - healthy balanced diet is consumed by upper class more often, comparing to lower class, as well as capacity to act and possibilities for selfrealization, and life quality dynamic understanding are valued more at upper middle class, compared to lower and lower middle class.

\section{Conclusions}

Life quality of new-borns, which is influenced by parent's reproductive health and lifestyle, which in healthy lifestyle context is viewed as balanced nutrition and eradication of bad habits, can be achieved with early preventive educational work, because special risk group are young, unmarried, smoking, little-educated mothers. Society development potential improves at schools, but value and life style fundaments are founded in family. To promote healthy diet social educational campaigns should be improved, as well as institutional solutions for derogation of bad habits.

To promote healthy lifestyle and healthy eating habits complex cooperation between parents, educational workers and other social institution representatives should be introduced, in order to provide sustainable life quality.

For the interested cooperation partners life-long learning should be directed towards success strategy, therefore diminishing the survival effect.

As a priority to promote children and youngster health education as an alternative to prohibitions and limitations, which shall rise the capacity to act.

Social stratification creates conditions for poverty trap, which is the main threat for life quality; in order to diminish social stratification it is necessary to carry out responsible policy, creating economic system and cultural environment that motivates learning. 


\section{References}

1. Ares G., Giménez A., Vidal L., Zhou Y., Krystallis A., Tsalis G., Symoneaux R., Cunha L. M., de Moura A. P., Clare A., Guerrero L., Cardello A. V., Wright A., Jefferies L., Lloyd M., Oliveira D., Deliza R. (2016) Do we all perceive food-related wellbeing in the same way? Results from an exploratory cross-cultural study. Food Quality and Preference, Vol. 52, p. 62-73.

2. Barrett C. (2002) Food Security and Food Assistance Programs. In: B.L. Garder B. L., Rausser G. (eds.) Handbook of Agricultural Economics Vol. 2b. Amsterdam: Elsevier.

3. Behrman J., Deolalikar A. (1990) The Intrahousehold Demand for Nutrients in Rural South India: Individual Estimates, Fixed Effects, and Permanent Income. Journal of Human Resources, Vol. 25 (4), p. 665-696.

4. Biagi B., Lambiri D., Royuela V. (2006) Quality of Life in the economic and Urban Economic Literature. CUEC Working Papers.

5. Blackwell L. R., Miniard P. W., Engel J. F. (2001) Consumer behavior. Mason, Ohio: South Western.

6. Cawley J. (2004) The Impact of Obesity on wages. Journal of Human Resources, Vol.39 (2), p. 451-474.

7. Cutler D. M., Glaeser E. L., Shapiro J. M. (2003) Why have Americans become more obese? Journal of Economic Perspectives, Vol. 17, p. 93-118.

8. Dias S. R. (2003) Gestão de marketing. São Paulo: LTC Saraiva.

9. Ferrell B. R., Hassey-Dow K., Grant M. (1995) Measurement of the QOL in Cancer Survivors. Quality of Life Research, Vol. 4, p. 523-531.

10. Grunert K. Dean D., Raats M., Nielsen N., Lumbers M. (2007) A measure of satisfaction with food-related life. Appetite, Vol. 49 (2), p. 486-493.

11. Guillemin I., Marrel A., Arnould B., Capuron L., Dupuy A., Ginon E., Laye S., Lecerf J. M., Prost M., Rogeaux M., Urdapilleta I., Allaert F. A. (2016) How French subjects describe well-being from food and eating habits? Development, item reduction and scoring definition of the Well-Being related to Food Questionnaire. Appetite, Vol. 96, p. 333--346.

12. Hasan L. (2007) On Measuring Complexity of Urban Living MPRA. Pakistan Institute of Development Economics. [accessed on 14. 02. 2017.] Available at: https://mpra.ub.uni-muenchen.de/7413/

13. Hawkins D. I., Mothersbaugh D. L., Best R. J. (2007) Consumer behavior: building marketing strategy. Rio de Janeiro: campus.

14. Jackson J. A., Kinn, S., Dalgarno, P. (2005). Patientcentred outcomes in dietary research. Journal of Human Nutrition and Dietetics, Vol. 18, p. 83-92.

15. Kotler P., Keller K. L. (2006) Marketing management. 12.ed. São Paulo: Prentice Hall.

16. Ķilis R. (2007) Sustainable development strategy of Latvia until 2030[accessed on 01. 03. 2010.] Available at: http://www.latvija2030.lv/upload/lias_pamatzinojums _lat.pdf (in Latvian)
17. Lanteigne C. A. (2005) Quality of Life in Cities. The University of New Brunswick.

18. Markausa I. M., Medveckis A., Pavlina I. (2007) Newborn life quality perspective - study in Kurzeme and Liepaja. Liepaja: Liepajas Pedagogijas akademija, Sociologisko petijumu centrs, p. 70. (in Latvian)

19. Markausa I. M., Medveckis A., Pavlina I. Romanuka L. (2008) Study on population reproduction qualitative aspect in Kurzeme and Liepaja, part II. Liepaja: Liepajas Universitates Sociologisko petijumu centrs, 64 p. (in Latvian)

20. Markausa I. M., Medveckis A., Romaņuka L. (2011) Youngsters' future plans and their implementation possibilities in Kurzeme and Liepaja. Population reproduction study in Kurzeme and Liepaja, part III. Liepaja: Liepajas Universitates Sociologisko petijumu centrs, 93 p. (in Latvian)

21. Meiselman H. L. (2016) Quality of life, well-being and wellness: Measuring subjective health for foods and other products. Food Quality and Preference, Vol. 54, p. 101-109.

22. Menssikovs V. (2006) Quality of life in Daugavpils. Quality of Life in Latvia, Riga: Zinatne, p. 153-178 (in Latvian)

23. Mezinska S. (2006) Non-specialist perceptions of health and their link to quality of life. Quality of Life in Latvia, Rìga: Zinatne, p. 217-236. (in Latvian)

24. National Development Plan of Latvia for 2014-2020. [accessed on 22. 02. 2017.] Available at: http://www.pkc.gov.lv/images/NAP2020\%20dokumenti/ 20121220_NAP2020_apstiprinats_Saeima.pdf

25. Pitt M. M, Rosenzweig M. R. Hassan N. (1990) Productivity, Health and Inequality in the Intrahousehold Distribution of Food in Low-Income Countries. The American Economic Review, Vol. 80 (5), p. 1139-1156.

26. Rozkalne A. (2006) Construction of "Good Life" in Latvian press. Quality of Life in Latvia, Rīga: Zinatne, $\mathrm{p}$. 295-318. (in Latvian)

27. Schnettler B., Miranda H., Lobos G., Orellana L., Sepulveda J., Denegri M., Etchebarne S., Mora M., Grunert K. G. (2015) Eating habits and subjective well-being. A typology of students in Chilean state universities. Appetite, Vol. 89, p. 203-214.

28. Seed P., Lloyd G. (1997) Quality of Life. London: Jessica Kinglsey Publishers.

29. Sheth J. N., Mittal B., Newman B. I. (1999) Customer behavior. Consumer behavior and beyond. Fort Worth, TX, The Dryden Press. Harcourt Brace College Publishers.

30. Siekierski P., Ponchio M. C. (2014) Lifestyles Related to Eating Habits in Ready Meal Consumption: Comparative Study Between São Paulo and Rome. New York: Nova Science Publishers.

31. Tisenkopfs T. (2006) What does good life means in modern Latvia? Quality of Life in Latvia, Rīga: Zinatne. (in Latvian)

32. Wells W. D., Tigert D. J. (1971) Activities, interests and opinions. Journal of Advertising Research, Vol. August, p. 27-35. 